\section{Applying Preferential Flow Concepts to Horticultural Water Management}

\author{
John S. Selker ${ }^{1}$
}

Additional index words. macropore, finger, funnel, contamination, groundwater

Summary. Avoiding groundwater contamination from agricultural activities is possible only if the processes that control deep percolation are understood. The source of contaminant movement to groundwater is typically through preferential flow, processes by which the bulk soil is bypassed by some part of the infiltrating water. Three mechanisms give rise to preferential flow: fingered flow, funnel flow, and macropore flow. Fingered flow occurs in coarse textured soils and can be minimized by starting with an initially wellwetted profile. Funnel flow is likely in layered soil profiles of silt or coarsertextured soil, in which avoiding slow overirrigation is critical. Macropore flow is observed in all structured soils in which maintaining irrigation rates well below the saturated conductivity of the soil is essential. These prescriptions are quite different than conventional recommendations, which fail to consider groundwater protection.

T he quantitative study of the movement of water through soils is well over 100 years old (e.g. Lawes et al. 1882), and continues to be an area of active research. This interest generally stems from two concerns:

'Department of Bioresource Engineering, Gilmore Hall, Oregon State University, Corvallis, OR 97331-3906.

The cost of publishing this paper was defrayed in part by the payment of page charges. Under postal regulations, this paper therefore must be hereby marked advertisement solely to indicate this fact.
1) how to manage soil water to obtain the greatest crop response and production; and 2) how to minimize the impact of cropping activities on the environment.

Until the 1970s, most of the research concerning soil water movement concentrated on attempts to predictflowin homogeneous soils (Gardner, 1958; Green and Ampt, 1911; Philip, 1969). This approach was used notbecauseit was thought to be the most realistic representation of soils, but because it allowed the application of powerful mathematical tools to solve some fundamental problems. In the 1970s, the first widespread observations of groundwater contamination were noted. Although the most famous of these cases (e.g., Love Canal) were due to industrial sources, agricultural activities al so havebeen implicated. In many of thesecases contamination would not have been predicted to reach the aquifer using models that assumed homogeneous soil and uniform water content. These realizations led to the development of more realistic and complete descriptions of solute movement through soils. The unaccounted for and widespread behavior of water moving unevenly through soil is described as preferential flow. These processes allow some of theinfiltrating water to percolatemorequickly than if the soil were uniformly carrying flow.

This article summarizes the research findings that explain these transport processes, providing horticulturists guidelines to enhance efficient use of water , increase efficiency of salinization control, and minimize groundwater contamination.

\section{Fingered flow}

Hill and Parlange (1972) noted that in coarsetextured soils water tends to move in isolated regions, or fingers of flow. This process is recognized as an instability in the wetting front, analogous to the instability in the darting tongues of a flame, or the flapping of a flag. This process was soon put into the mathematical framework of linear instability theory (Parlange and Hill, 1976), which has since been shown to provide reasonable estimates of the physical dimensions (i.e., width) of these fingers of flow (Glass et al., 1989; Selker et al., 1992).

From a practical point of view, the fact that the width of fingers can be predicted is useful. It confirms that our conceptual model for fingered flow is capturing the physical basis of the process. From this position of confidence, we then can use this result to see where fingers are likely to be prominent. The size of fingers is related inversely to the characteristic grain size of amedium (Fig. 1): when the soil has atexture of silt or finer, the finger dimensions are predicted to be $>1 \mathrm{~m}$. Fingered flow occurs only in unstructured soils. Hence, fingered flow is expected only in soils that are predominantly sand.

Finger width is not strongly affected by the 
flux through the system (Fig. 1). Rather, the flux through the system typically affects the number of fingers that form. When the flux is increased up to the rate of the saturated conductivity of the soil, the fingers will grow in width and frequency to the point at which they finally merge to yield a flat wetting front without fingered properties. Since most sandy soils have extremely high conductivity compared to naturally occurring infiltration rates, this rarely occurs in natural conditions.

Understanding effects of prior moisturecontent on finger formation and finger persistence is important in managing production on sandy soils. As shown by Lui et al. (1993), when soil is at field capacity, fingers will be about 10 -fold wider than those developing in dry conditions. Thus, if a sandy soil is not allowed to dry completely, the bypassing effect will be reduced, if not entirely eliminated. I saw a pertinent example of theimportance of this observation in Florida. Using a drip system, when irrigation was initiated before the field had significantly dried in thespring, theyear's crop did well. In years when irrigation was delayed until the soil was dried, narrow fingers formed through the root zone, leaving most of the soil dry, thus damaging the crop.

Once a finger has formed in a particular location, it will remain (persist) until the soil has either dried entirely or has been completely saturated (Glass et al., 1989). Given the very high conductivity of sandy soils, eliminating persistent fingers requires either drying from the surface, which is effective to a maximum depth of about 1 $\mathrm{m}$, or raising the water table. A striking example of the impact of persistence was seen in Lafayette, Ind. (Fig. 2). Distinct fingers of flow were made visible in the coarse material due to the chemical weathering of the calcareous material. Within the fingers, pebbles were readily crushed manually, while outside of the fingers the gravel strength was typical of unweathered material. Clearly these fingers had persisted for many decades.

It is crucial when initiating irrigation on dry, sandy soils that the rate of irrigation is nearly that of the saturated conductivity of the soil, so the profile starts off from an entirely wetted condition. From this initial state, any fingers will be quite largeand likely not a problem from a production or contamination point of view. If problematic fingered flow is found, it can be eliminated only through complete soil drying or saturation. Given the length of time required for total drying, achieving abrief period of saturation is the most practical approach to eliminate fingered-flow pathways.

\section{Macropore flow}

Aside from very sandy soils, al most all other soils have macroscopic structure. In addition to grouping soil particles into larger units, there are structures that arise from plant and fauna activities, leaving root channels, worm holes, and animal burrows. These structural elements consist of pores that are generally several orders of magnitude larger than the characteristic grain size of the soil. For instance, in a silty soil with a median pore size of $1 \times 10^{-5} \mathrm{~m}$, the interped face spacing would be of the order of $1 \times 10^{-4} \mathrm{~m}$, and it would have deep root channels $1 \times 10^{-3} \mathrm{~m}$ in diameter. Such connected systems of largepores are referred to as macropores

Before the 1980s, these soil features were not considered in the prediction of movement through soils. Under most natural rainfall conditions the water would go through the bulk soil, never reaching a point of saturation at which these pores would fill. However, during intense rainfall and typical irrigation conditions, the soil is taken to a state of near saturation, and these pores do fill. This results in adramatic increase in conductivity, as the resistance to flow decreases with the square of the aperture size. Thus, such macroscopic features can dominate flow during periods of intense infiltration (asingle 1-mm porewill carry as much water as about $1 \mathrm{~m}^{2}$ of uniformly packed silt textured media). Beyond the ability to allow greater infiltration, these pores allow chemicals to bypass the bulk of the soil. In this way, chemicals that would bepredicted to moveslowly through thesoil profile can move quickly to shallow aquifers. Broadly referred to as macroporeflow, this mechanism has been studied widely in thelast 2 decades, and has been shown to have a major impact on the transport properties of most soils (German and Beven, 1981; Gish and Jury, 1983).

\section{Funnel flow}

Many soils are generated by deposition of material by either processes of wind, water, or volcanic activity, yielding a layered character with alternating series of finer and coarser texture due to variation in the source of the material and energy of the flow at the time of deposition. These layers have a strong effect on infiltration of water due to the capillary properties that depend on the pore size distribution in each layer. Although soils with coarser texture will typically have higher saturated conductivity, this rule breaks down in the context of unsaturated flow.

To understand this, it is useful to visualize a pair of stacked sponges, where the bottom sponge is of very poor quality with large pores, and the top sponge is of excellent quality with very fine pores. If the stack of sponges is at a slight angle and water is poured slowly onto the stack, the high-quality sponge will retain the water and let it flow over the lower-quality sponge. Similarly, in thelayered soil system, the finer-textured pores will retain infiltrating water and divert the water over the coarser layer. This process, known as funnel flow, can intercept infiltration from broad areas into focused streams of infiltration (Kung, 1990). In a potato field studied in Wisconsin, water landing on an area of $2500 \mathrm{~m}^{2}$ was focused to an area $<0.25 \mathrm{~m}^{2}$ by the time it reached the water table at a depth of $6 \mathrm{~m}$ (Kung, 1990). This 10,000-fold reduction of area of flow gives riseto aproportionally increased vertical transport velocity, dramatically reducing the time of travel of water and solutes from the soil surface to unconfined aquifers.

\section{Management guidelines}

As shown above, there are processes that can cause a portion of the water to leave the root zone rapidly through a small portion of the profile in soils of all textures. The key to preventing groundwater contamination is to use our understanding of theseflow processes as a parameter in our irrigation management.

Traditionally the irrigation system designers' concerns were dominated by the following:

Fig. 1. Dependence of finger width on the characteristic grain size of a soil and the relative flux $(q / K s)$ into the system (using the results of Parlange et al., 1990).

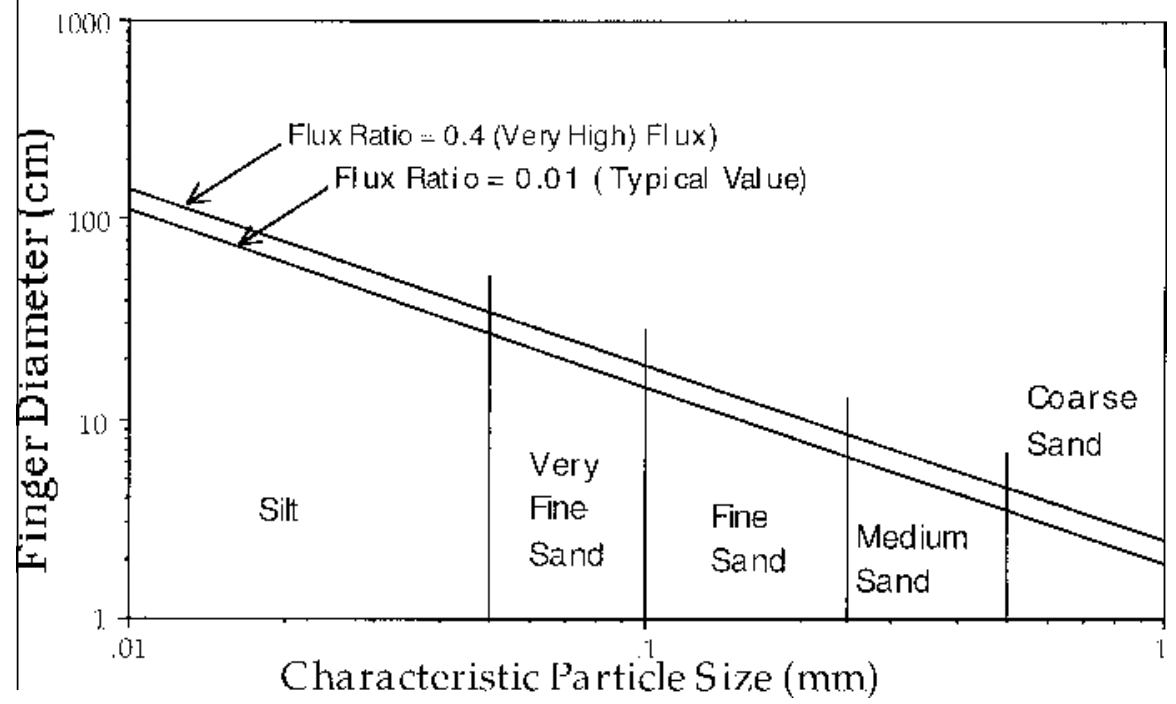


1. Selecting a system that will work with the topography of the land (e.g., can't useflood irrigation on rolling hills).

2. Selecting a system that suits the cropmachinery system the farmer uses.

3. Choosing application rates that suit the infiltration capacity of the soil (in flood irrigation, this means that the application rateshould bemuch higher than theinfiltration capacity).

Irrigation efficiency was typically of paramount interest, as water is typically a scarce commodity, either due to pumping costs, or overall supply.

In the past 3 decades, preventing environmental degradation has joined the list of decisive concerns to agriculturists. Irrigation system designers have aided in environmental protection through improved irrigation uniformity: If afield is not being irrigated uniformly, and yet all points

Fig. 2. R. Bryant stands next to glossic features in a soil believed to have been formed as a result of fingered flow that persisted for periods of hundreds, if not thousands, of years. The apparent difference in coloration in the fingers is not due to moisture content, but results from the extensive chemical weathering of the material within the fingers. become fully irrigated, there will be regions of excess irrigation that will contribute percolation to the groundwater. This line of argument still only considers movement in the absence of preferential flow, and few have addressed the issue of how understanding preferential flow should influence irrigation operation.

To address the impact of preferential flow on irrigation, consider the case of irrigating a coarse soil. There are two forms of preferential flow that should be expected: fingered flow and funnel flow. Irrigation on coarse-textured soils typically uses overhead sprinkler or drip irrigation, as surface irrigation methods (e.g., flood and furrow irrigation) are not amenable to the high infiltration capacities of these soils. At the start of the irrigation season thefirst consideration must beto avoid finger formation in the root zone by ensuring that the root zone starts in a moist condition. If the soil is starting from adry condition, aburst of irrigation at a rate close to saturated conductivity of the soil of sufficient amount to wet the root zone will erase any residual fingers and render the profile far less susceptible to new finger development. From this point, the profile should not be allowed to dry completely during the irrigation season.

Using a drip irrigation system, such a process can involve great additional expense and,

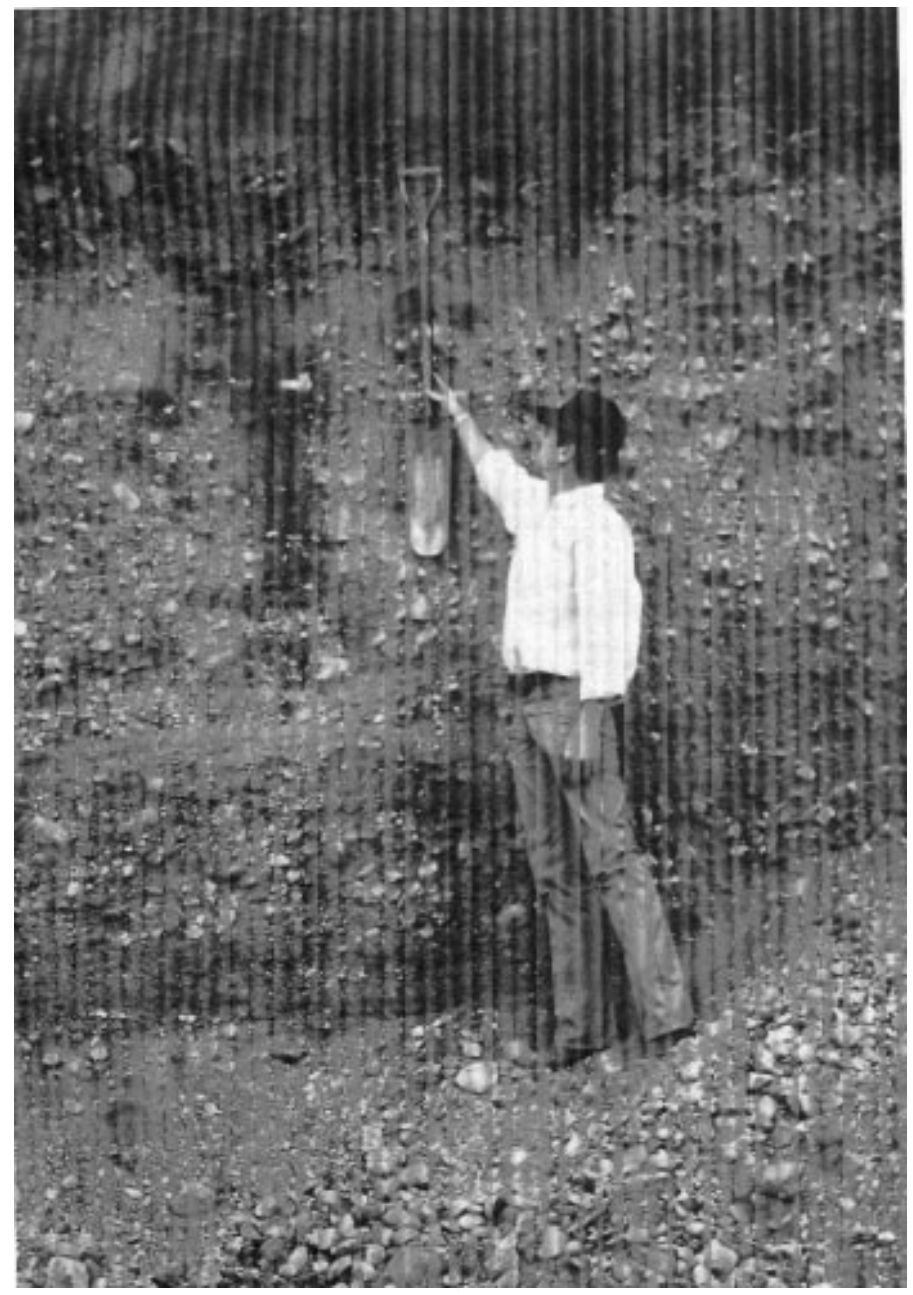

therefore, be impractical. In fingered flow, water from drippers is likely to go vertically downward in apath of area equal to the saturated conductivity of the soil divided by the application rate. For instance, a 5 -liter $\cdot \mathrm{h}^{-1}\left(0.005 \mathrm{~m}^{3} \cdot \mathrm{h}^{-1}\right)$ emitter in a coarse soil with conductivity of $1 \mathrm{~m} \cdot \mathrm{h}^{-1}$ will keep a column of soil wet with a cross-sectional area of about $50 \mathrm{~cm}^{2}$. If the plant roots go to a depth of 0.5 $\mathrm{m}$, the irrigated volume of soil is just 2.5 liters (to determine finger size on a site, simply drip about 20 liters of dyed water onto an area of completely dry sand and measure the diameter of the wetted area through excavation). If this soil had a field capacity of about $10 \%$, any application above 0.25 liter would be lost below the root zone. In such a case the system must be operated in bursts of 3 min at a time; long enough to refill 0.25 liter of holding capacity. The next irrigation would be required when the plant had transpired this volume. This high-frequency, low-volume approach is well adapted to drip irrigation, but, if ignored, water waste and aquifer contamination, particularly if chemigation is used, is likely.

Still considering coarse soils, what are the prescriptions to handle the possibility of funnel flow? Two management practices can be used to minimize the effects of funnel flow. The first practice is applying high rates of water. The funneling only occurs when the flow is slow enough for the fine layers to carry water laterally under unsaturated conditions, and the high rate of application lets water cross through the fine layers into the coarse. The second practice is applying water for a short duration with high frequency. Irrigating to keep the top $30 \mathrm{~cm}$ well wetted would be suitable for most annual crops. If a longer period of irrigation is used, the water will end up being restricted by an upper, fine layer, then funneled by a lower, fine layer. The worst prescription for sites with layered soils is slow over-irrigation.

In the case of finer, structured soils, macropore flow must be avoided. Macropore flow occurs when water is applied at rates that approach the infiltration capacity of the soil in a given horizon. In this case, the prescription is exactly opposite of that for coarse soils: apply the water as slowly as required to avoid saturating the soil. In the case of a clay soil, macropore flow was eliminated by reducing the irrigation rate to 0.0003 $\mathrm{m} \cdot \mathrm{h}^{-1}$ (Selker et al., 1995). These extremely low rates of irrigation may be achieved by pulsing the irrigation system or by using emitters designed to provide continuous low-rate irrigation.

\section{Conclusions}

Many aquifers have been contaminated through ignorance of the possibility of rapid flow of water through soils. Such preferential flow can be avoided by following a few simple rules that depend on the nature of the soil at the site. These rules are different from what one might expect using native intuition, and thus have long been 
violated by irrigation system designers and operators. When understood, preferential flow can be avoided to save water and protect aquifers underlying agricultural lands.

\section{Literature Cited}

Gardner, W.R. 1958. Some steady state solutions of the unsaturated moisture flow equation with application to evaporation from a water table. Soil Sci. 85:228-232.

Gish, T.J. and W.A. Jury. 1983. Effect of plant roots and root channels on solute transport. Trans. ASAE 26(2):440-444, 451.

German, P. and K. Beven. 1981. Water flow in soil macropores. I. An experimental approach. J. Soil Sci. Soc. 32:1-13.

Glass, R.J, T.S. Steenhuis, and J.-Y. Parlange. 1989. Mechanism for finger persistence in homogeneous, unsaturated, porous media: Theory and verification. Soil Sci. 148(1):60-70.
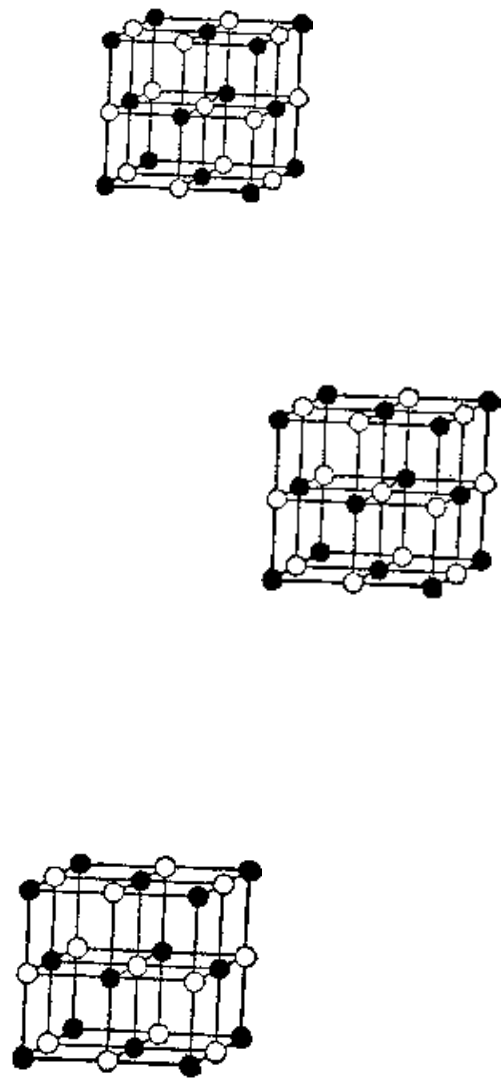

Green, W.H. and G.A. Ampt. 1911. Studies in soil physics. I. The flow of water and air through soils. J. Agr. Sci. 4:1-24.

Hill, D.E. and J.-Y. Parlange. 1972. Wetting front instability in layered soils. Soil Sci. Soc. Amer. Proc. 36:697-702.

Kung, K-J.S. 1990. Preferential flow in a sandy vadose soil: I. Field observations. Geoderma $46: 51-58$

Lawes, J.B., J.H. Gilbert, and R. Warrington. 1882 On the amount and composition of rain and drainagewaters collected at Rothamsted. William Clowes and Sons, London.

Lui, Y., B.R. Bierck, J.S. Selker, T.S. Steenhuis, and J-Y. Parlange. 1993. High intensity X-ray and tensiometer measurements in rapidly changing preferential flow fields. Soil Sci. Soc. Amer. J. 57:1188-1192.

Parlange, J.-Y. and D.E. Hill. 1976. Theoretical
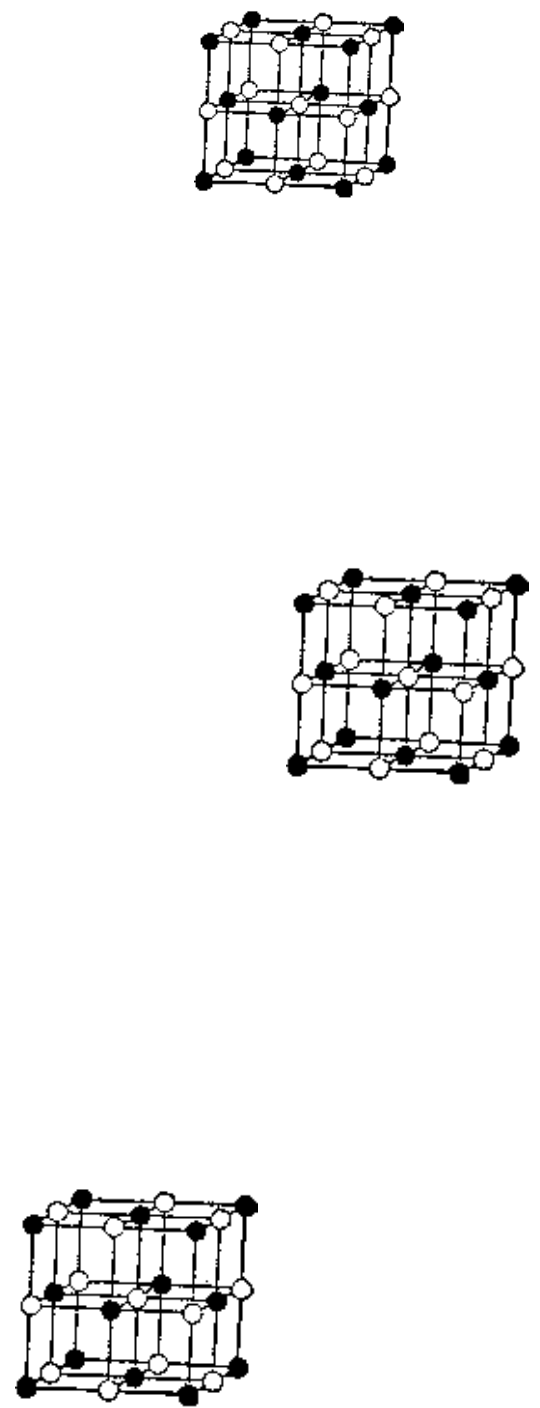

analysis of wetting front instability in soils. Soil Sci. 122:236-239.

Parlange, J.-Y, R.J. Glass, and T.S. Steenuis. 1990. Application of scaling to the analysis of unstableflow phenomena. Scaling in soil physics. Spec. Publ. 25, Soil Sci. Soc. Amer., Madison, Wis.

Philip, J.R. 1969. Theory of infiltration. Adv. Hydrosci. 5:215-296.

Selker, J.S., T.S. Steenhuis, and Y.-J. Parlange. 1992. Fingered flow in unlayered media under uniformirrigation. Soil Sci. Soc. Amer. J. 56:13461350.

Selker, J.S., W. Cao, and R. Roseberg. 1995. Use of ultralow rate application devices to eliminate macropore flow during irrigation. Proc. 5th Intl. Microirr. Congr., 2-6 Apr. 1995, Orlando, Fla. ASAE Publ. 4-95. p. 54-59.
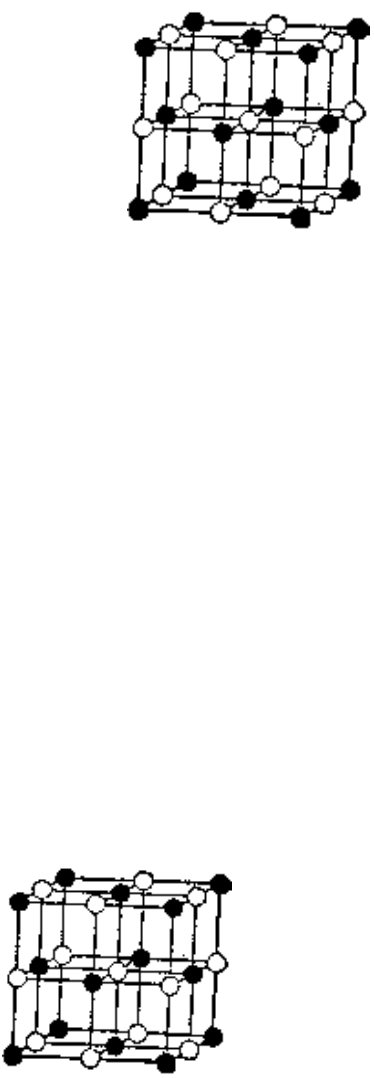